\title{
YOGA as a Potential Mind-Body Medicine for Circadian Rhythm Restoration for Cancer Patients
}

\author{
Yu Huei Liü ${ }^{1,2 *}$ \\ ${ }^{1}$ Graduate Institute of Integrated Medicine, China Medical University, Taichung, Taiwan \\ ${ }^{2}$ Department of Medical Genetics and Medical Research, China Medical University Hospital, Taichung, Taiwan
}

*Corresponding author: Yu-Huei Liu, PhD, Graduate Institute of Integrated Medicine, China Medical University, Taichung, Taiwan, Tel: +886-4-22052121 ext

204, Fax: 886-4-22033295, E-mail: yuhueiliu@mail.cmu.edu.tw

Received Date: December 18, 2019

Published Date: January 03, 2020

\section{Short Communication}

Cancer patients receiving chemotherapy suffer from a variety of side effects, including insomnia [1], However, the underling mechanisms behind insomnia during and/or after chemotherapy are not yet fully understood. Both cancer and anticancer therapeutics alter the production of proinflammatory cytokines such as sleep inducers TNF- $\alpha$, IL- $1 \beta$ and IL-6, to change the immune responses depending on immune cells repertories, which subsequence function on the central nervous system and the sleepwake rhythms, by which to alter sleep behavior [2,3].

Currently no specific treatment for chemotherapy-related insomnia, nonprescriptive and prescriptive sleep medicines are the only way to choose even though those medications have not been evaluated in cancer patients. On the other hand, although dysfunction in circadian rhythms is a common occurrence in older adults and is a symptom of neurodegeneration [4], studies also suggest that circadian rhythm disruptions might potentially risk for developing neurodegenerative diseases such as Alzheimer's disease [5-7] and Parkinson's disease [7,8]. Although the causalrelationship requires to be evaluated in larger and longitudinal studies $[9,10]$, it points the importance to address chemotherapyrelated insomnia to improve patients' potentials to complete treatment for cancer, the recovery rate, and their quality of life.

Yoga is the original mind-body medicine that keeps physical homeostasis as well as mental and spiritual harmony in human. Several evidence-based mind-body medicine, including yoga, have been successfully used for the management of insomnia and have demonstrated efficacy in cancer patients receiving chemotherapy $[11,12]$. Indeed, yoga has been shown to improve sleep quality of chemotherapy-related insomnia especially for breast cancer patients [13-17], however, the underlying mechanism require to be identified. In addition, whether it is potent enough to manage chemotherapy-related insomnia for other cancer patients require further investigation. More high-quality randomized control trials to support the scientific evidence are warranted. This is what we eager to work on.

\section{Acknowledgment}

None.

\section{Conflict of Interest}

No conflict of interest.

\section{References}

1. Fiorentino L, Ancoli Israel S (2007) Sleep dysfunction in patients with cancer. Curr Treat Options Neurol 9(5): 337-346.

2. Kapsimalis F, Richardson G, Opp MR, Kryger M (2005) Cytokines and normal sleep, Curr Opin Pulm Med 11(6): 481-484.

3. Palesh O, Peppone L, Innominato PF, Janelsins M, Jeong M, et al. (2012) Prevalence, putative mechanisms, and current management of sleep problems during chemotherapy for cancer, Nat Sci Sleep 4: 151-162.

4. Videnovic A, Lazar AS, Barker RA, Overeem S (2014) The clocks that time us'--circadian rhythms in neurodegenerative disorders, Nat Rev Neurol 10(12): 683-693.

5. Kang JE, Lim MM, Bateman RJ, Lee JJ, Smyth LP, et al. (2009) Amyloidbeta dynamics are regulated by orexin and the sleep-wake cycle, Science 326(5955): 1005-1007.

6. Ooms S, Overeem S, Besse K, Rikkert MO, Verbeek M, et al. (2014) Effect of 1 night of total sleep deprivation on cerebrospinal fluid beta-amyloid 42 in healthy middle-aged men: a randomized clinical trial. JAMA Neurol 71(8): 971-977.

7. Musiek ES, Holtzman DM (2016) Mechanisms linking circadian clocks, sleep, and neurodegeneration, Science 354(6315): 1004-1008.

8. Chahine LM, Amara AW, Videnovic A (2017) A systematic review of the literature on disorders of sleep and wakefulness in Parkinson's disease from 2005 to 2015. Sleep Med Rev 35: 33-50. 
9. Leng Y, Musiek ES, Hu K, Cappuccio FP, Yaffe K (2019) Association between circadian rhythms and neurodegenerative diseases. Lancet Neurol 18(3): 307-318

10. Hood S, Amir S (2017) Neurodegeneration and the Circadian Clock, Front Aging Neurosci 9: 170.

11. Forbes D, Blake CM, Thiessen EJ, Peacock S, Hawranik P (2014) Light therapy for improving cognition, activities of daily living, sleep, challenging behaviour, and psychiatric disturbances in dementia, Cochrane Database Syst Rev 26(2): CD003946.

12. Sulli G, Manoogian ENC, Taub PR, Panda S (2018) Training the Circadian Clock, Clocking the Drugs, and Drugging the Clock to Prevent, Manage, and Treat Chronic Diseases, Trends Pharmacol Sci 39(9): 812-827.

13. Danhauer SC, Addington EL, Cohen L, Sohl SJ, Van Puymbroeck M, et al. (2019) Yoga for symptom management in oncology: A review of the evidence base and future directions for research, Cancer 125(12): 19791989.
14. Huberty J, Eckert R, Dueck A, Kosiorek H, Larkey L, e al. (2019) Online yoga in myeloproliferative neoplasm patients: results of a randomized pilot trial to inform future research, BMC Complement Altern Med 19(1): 121.

15. Matthews EE, Janssen DW, Djalilova DM, Berger AM (2018) Effects of Exercise on Sleep in Women with Breast Cancer: A Systematic Review, Sleep Med Clin 13(3): 395-417.

16. Lin PJ, Peppone LJ, Janelsins MC, Mohile SG, Kamen CS, et al. (2018) Yoga for the Management of Cancer Treatment-Related Toxicities, Curr Oncol Rep 20(1): 5 .

17.Zeichner SB, Zeichner RL, Gogineni K, Shatil S, Ioachimescu O (2017) Cognitive Behavioral Therapy for Insomnia, Mindfulness, and Yoga in Patients with Breast Cancer with Sleep Disturbance: A Literature Review, Breast Cancer (Auckl) 11: 1178223417745564. 